Article

\title{
Anthocyanin Characterization, Total Phenolic Quantification and Antioxidant Features of Some Chilean Edible Berry Extracts
}

Anghel Brito ${ }^{1}$, Carlos Areche ${ }^{2}$, Beatriz Sepúlveda ${ }^{3}$, Edward J. Kennelly ${ }^{4}$ and

Mario J. Simirgiotis ${ }^{1, *}$

1 Laboratorio de Productos Naturales, Departamento de Química, Facultad de Ciencias Básicas, Universidad de Antofagasta, Av. Coloso S-N, Antofagasta 1240000, Chile;

E-Mail: Anghel.Brito@gmail.com

2 Departamento de Química, Facultad de Ciencias, Universidad de Chile, Casilla 653, Santiago 7800024, Chile; E-Mail: areche@uchile.cl

3 Departamento de Ciencias Químicas, Universidad Andrés Bello, Campus Viña del Mar, Quillota 980, Viña del Mar 2520000, Chile; E-Mail: bsepulveda@uc.cl

4 Department of Biological Sciences, Lehman College and The Graduate Center, The City University of New York, 250 Bedford Park Boulevard West, Bronx, NY 10468, USA;

E-Mail: kennelly@lehman.cuny.edu

* Author to whom correspondence should be addressed; E-Mail: mario.simirgiotis@uantof.cl; Tel.: +56-55-637-229; Fax: +56-55-637-457.

Received: 17 June 2014; in revised form: 6 July 2014 / Accepted: 11 July 2014 /

Published: 28 July 2014

Abstract: The anthocyanin composition and HPLC fingerprints of six small berries endemic of the VIII region of Chile were investigated using high resolution mass analysis for the first time (HR-ToF-ESI-MS). The antioxidant features of the six endemic species were compared, including a variety of blueberries which is one of the most commercially significant berry crops in Chile. The anthocyanin fingerprints obtained for the fruits were compared and correlated with the antioxidant features measured by the bleaching of the DPPH radical, the ferric reducing antioxidant power (FRAP), the superoxide anion scavenging activity assay (SA), and total content of phenolics, flavonoids and anthocyanins measured by spectroscopic methods. Thirty one anthocyanins were identified, and the major ones were quantified by HPLC-DAD, mostly branched 3-O-glycosides of delphinidin, cyanidin, petunidin, peonidin and malvidin. Three phenolic acids (feruloylquinic acid, chlorogenic acid, and neochlorogenic acid) and five flavonols (hyperoside, isoquercitrin, quercetin, rutin, myricetin and isorhamnetin) were also identified. Calafate fruits showed the 
highest antioxidant activity $(2.33 \pm 0.21 \mu \mathrm{g} / \mathrm{mL}$ in the DPPH assay), followed by blueberry $(3.32 \pm 0.18 \mu \mathrm{g} / \mathrm{mL})$, and arrayán $(5.88 \pm 0.21)$, respectively.

Keywords: endemic berries; poliphenolics; quantitation; antioxidants; HPLC-MS; murtilla; calafate; chequen; arrayan; meli; luma; blueberry

\section{Introduction}

Fruits and vegetables are considered highly protective for human health, particularly against ageing and various oxidative-stress related diseases, due to their content of healthy phytochemicals [1]. Several epidemiological studies have highlighted the association between the consumption of foods with high contents of phytochemicals, mainly flavonols, phenolic acids and anthocyanins, and the prevention of degenerative diseases such as cardiovascular diseases, ageing, cancer and other degenerative disorders [2,3]. Anthocyanins are a group of red, purple, violet and blue water soluble polyphenolic pigments widely distributed in berry fruits which can act as antioxidants or free radical scavengers, thus preventing oxidative stress [4]. The term berry fruit generally refers to some small fruit that lacks big seeds and can be eaten whole. Berry fruits are often the richest source of antioxidant phytochemicals among fruits and vegetables [5], thus the chemical study of native berry fruits is of great economic significance since it can support the consumption and commercial activities of gatherers, growers, micro-companies and industries associated with the use of native plants. Chilean fruits such as arrayán, chequen, calafate, meli, maqui and murta (Figure 1) are small pigmented native berries which were collected since pre-Colombian times by South American Amerindians as a food source. At present, there is still some regional consumption of the small berries from trees and shrubs belonging to the Myrtaceae (Chilean myrtle, murta, arrayán, chequén, luma and meli), Berberidaceae (michay and calafate) as well as Eleaocarpaceae (maqui) occuring in southern Chile and Argentina. In Chile, "murta" or "murtilla" (Myrtus ugni Molina or Ugni molinae Turczaninov), a wild perennial shrub also commonly known as Chilean guava, is the best-known of the native Myrtaceae plants, where the people have long appreciated its red edible berries for its unique aroma. Infusions of the leaves of this species are anti-inflammatory and analgesic [6] and the fruits contain several volatile compounds responsible for the aroma [7].

Arrayán (Luma apiculata (DC.) Burret is an evergreen Myrtaceae tree occurring in southern Chile and Argentina of about $10 \mathrm{~m}$ in height with orange-red trunk and edible purple black berries, $1-1.5 \mathrm{~cm}$ in diameter, that ripen in early autumn and are half the size, with more intense color, but similar aspect and consistence as the worldwide commercialized blueberries (Vaccinium corymbosum). Murillo [8] describes the medicinal properties of Eugenia apiculata D.C. (a synonym for L. apiculata, also known as Myrceugenella apiculata (DC.) Kausel [9]). The traditional use indications include aromatic, slightly astringent, balsamic and anti-inflammatory uses. The fruits were used to prepare liquor. This information is in agreement with the aromatic flavor that is attractive for local producers of alcoholic beverages. The fruits of Luma chequén (Molina) A. Gray, syn: Myrceugenella chequen (Mol.) Kaus are edible small berries with similar size than those of arrayán and murta. de Mösbach [10] refers to uses of $L$. chequen in infusions and syrups as an astringent. The traditional use indications in traditional 
medicine can be related to the tannin content of the plant which is also recommended as a wound wash and to treat dysentery. Both L. apiculata and L. chequen fruits were used to prepare "chicha", a South American native fermented beverage [9]. Calafate or Magellan barberry (Berberis microphylla G. Forst, sin. Berberis buxifolia, and Berberis heterophylla) is another Patagonian shrub with edible dark small berries that can grow in a great variety of areas [11]. The production of calafate is concentrated in small gardens in the Regions of Aysén and Magallanes for local production of jams and juices [11]. This fruit contains several anthocyanins [12] and high content of cinnamic acids [13]. Maqui (Aristotelia chilensis) fruit is now one of the most famous dark colored Chilean berries because of its high content of anthocyanins [14]. Calafate, maqui and murta are antioxidant berries considered superfruits due to their high content of phenolic compounds, including several anthocyanins [6,12,15]. Several edible Myrtaceae fruits known worldwide present free radical scavenging constituents including anthocyanins [16], while Chilean Myrtaceae with high anthocyanin contents have been assessed for antioxidant activity and showed good antioxidant features [17-19]. Mass spectrometry has undergone tremendous technological improvements in the last years, especially with the development of ionization methods such as electrospray (ESI), atmospheric pressure chemical ionization (APCI) and high resolution mass detectors such as time of flight (TOF). Indeed, several antioxidant phenolics in edible plants [20]; fruits [21-23]; nuts [24] and food byproducts [25] were analyzed using HPLC hyphenated with accurate high resolution time of flight analyzers (HPLC-PDA-ToF-MS). However, the chemical analysis regarding anthocyanins or metabolomics present in wild Chilean berries including arrayán, chequén, murta, and calafate was performed using low resolution methods (ESI-ion trap-MS) [12,15,19], while the phenolic constituents of $A$. meli have not beenreported to the best of our knowledge.

Figure 1. Pictures of (a) chequén, (Luma chequén) (b) murta, (Ugni molinae) (c) arrayán, (Luma apiculata), (d) blueberries, (Vaccinium corymbosum) (e) meli, (Amomyrtus meli and (f) calafate (Berberis microphylla) growing in the VIII region of Chile.

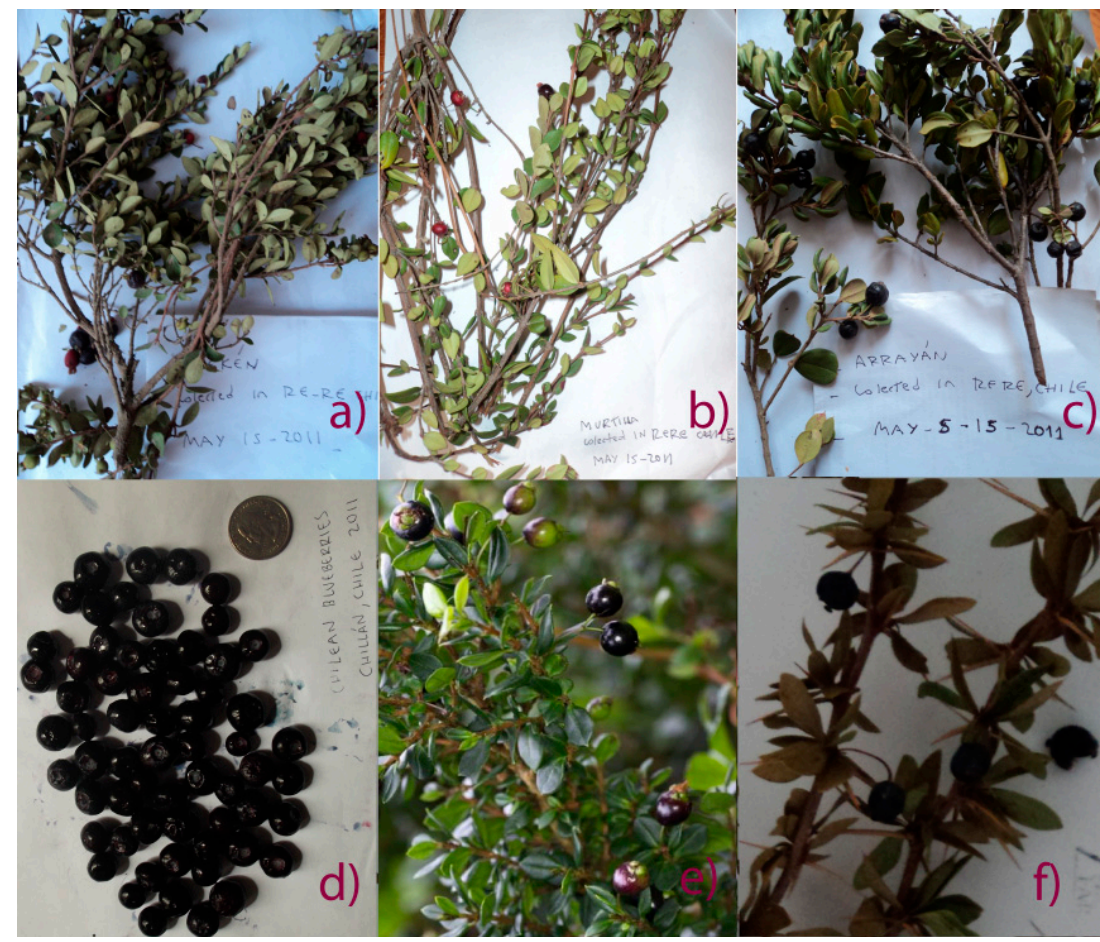


The aim of the present work was the analysis by high resolution mass spectrometry (HR-MS) of some important native berries from Chile, and the comparison of the antioxidant properties and total phenolics. In the present work the anthocyanin fingerprints and polyphenolic content of six small Chilean berries (arrayán, chequén, murta, calafate, meli and Chilean blueberry var. Brigitta, Figure 1) from the VIII region of Chile were compared and correlated with the antioxidant capacities measured by the DPPH radical bleaching, ferric reducing antioxidant power (FRAP), and the superoxide anion scavenging activity (SA) assays. The anthocyanins in berries were identified for the first time with the help of PDA analysis and high resolution time of flight mass spectrometry (HPLC-ESI-ToF-MS) plus comparison with authentic standards.

\section{Results and Discussion}

\subsection{Accurate MS-PDA Identification of Anthocyanins in Six Small Berry Fruits from Southern Chile}

Anthocyanins in berry fruits were accurately detected and identified using HPLC with UV-visible detection (PDA, Figure 2, Table 1) and high resolution time of flight mass spectrometry (HR-ToF-MS, Table 1). The 31 anthocyanins identified in the six berries (Figure 3) were mainly 3-O-glycoside conjugates and their derivatives.

Figure 2. HPLC-PDA chromatograms of six berries from the VIII region of Chile. (a) Vaccinium corymbosum, (b) Berberis microphylla, (c) Ugni molinae, (d) Luma chequén, (e) Luma apiculata, and (f) Amomyrtus meli monitored at $520 \mathrm{~nm}$. Peaks numbers refer to those indicated in Table 1.
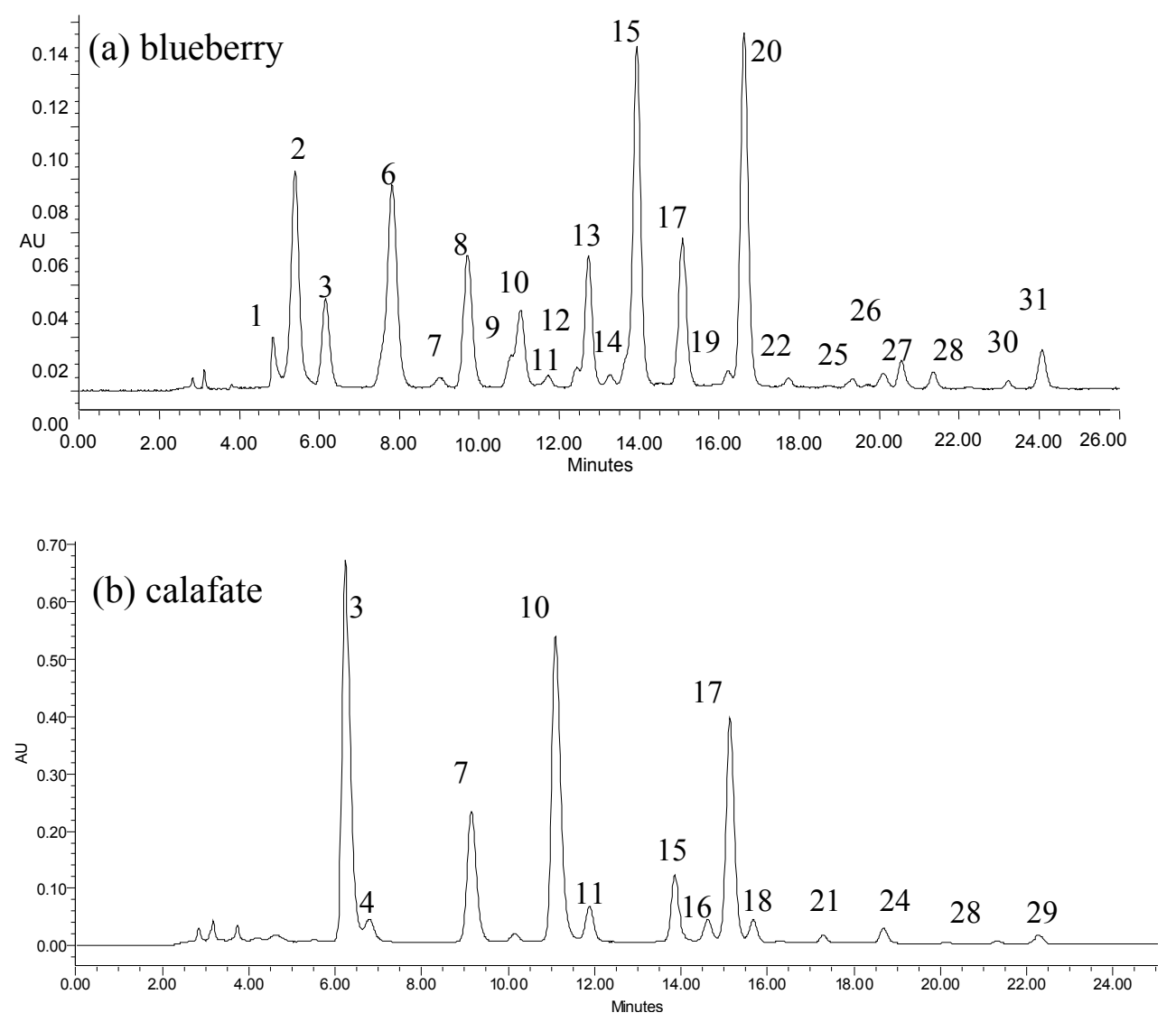
Figure 2. Cont.
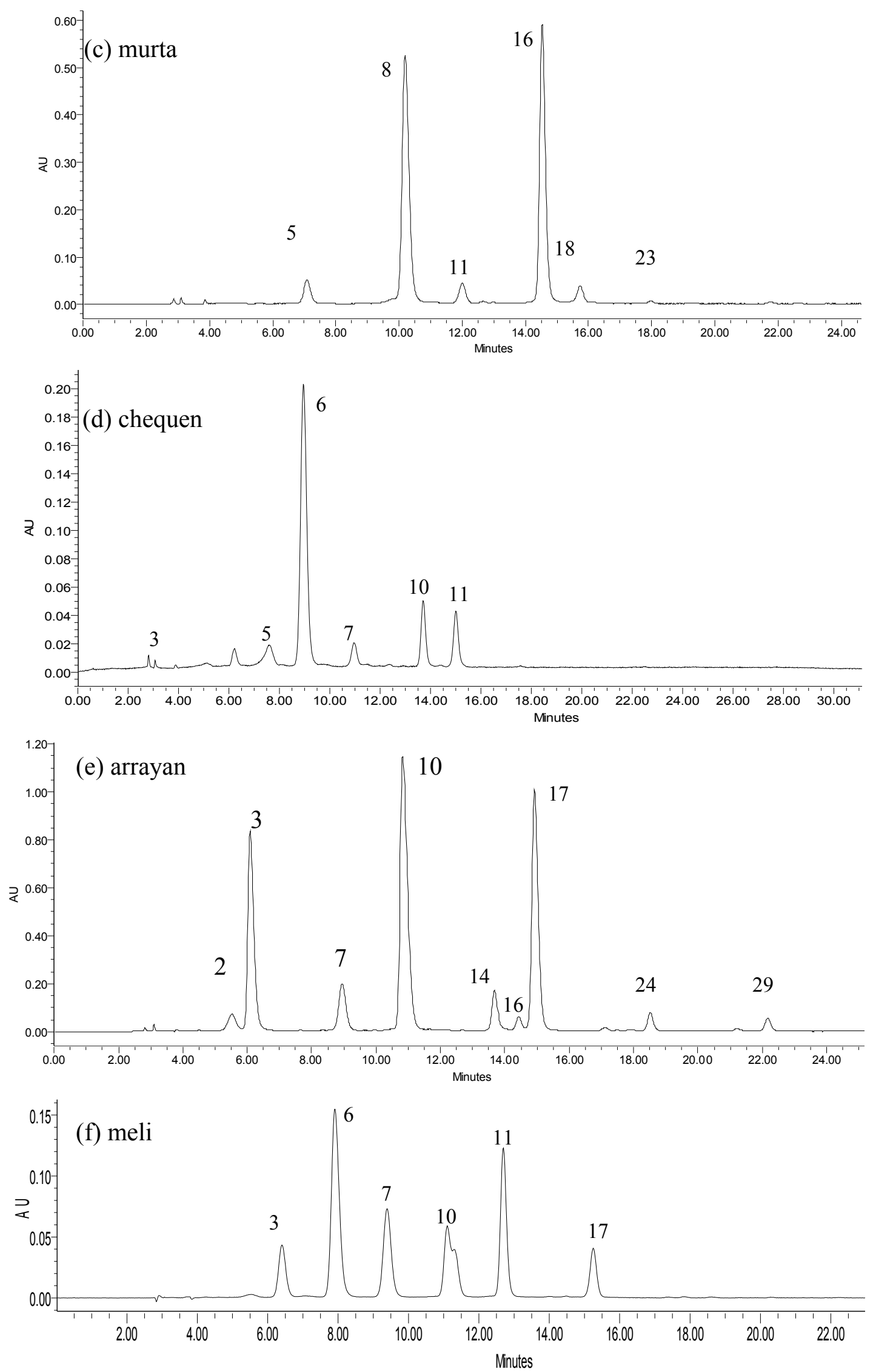
Figure 3. Structures of the anthocyanins identified in six berries from the VIII region of Chile.<smiles></smiles>

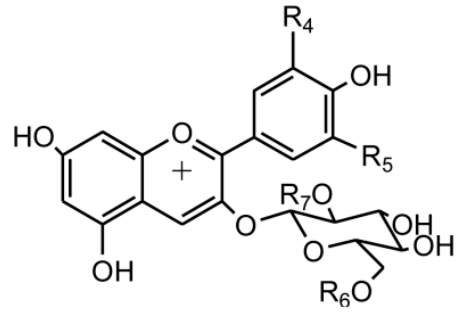

$\begin{array}{lllllllll}\text { Peak } & \mathbf{R}_{1} & \mathbf{R}_{2} & \mathbf{R}_{3} & \text { Peak } & \mathbf{R}_{4} & \mathbf{R}_{5} & \mathbf{R}_{6} & \mathbf{R}_{7} \\ \mathbf{3}^{*} & \mathrm{OH} & \mathrm{OH} & \mathrm{Gal} & \mathbf{1} & \mathrm{OH} & \mathrm{OCH}_{3} & \mathrm{Glu} & \mathrm{H} \\ \mathbf{4} & \mathrm{OH} & \mathrm{OH} & \mathrm{Glu} & \mathbf{2} & \mathrm{OH} & \mathrm{OCH}_{3} & \mathrm{Glu} & \mathrm{H} \\ \mathbf{6}^{*} & \mathrm{OH} & \mathrm{H} & \mathrm{Gal} & \mathbf{5} & \mathrm{OH} & \mathrm{H} & \mathrm{Rha} & \mathrm{H} \\ \mathbf{7}^{*} & \mathrm{OH} & \mathrm{H} & \mathrm{Glu} & \mathbf{8} & \mathrm{OH} & \mathrm{OCH}_{3} & \mathrm{Rha} & \mathrm{H} \\ \mathbf{9} & \mathrm{OCH} & \mathrm{OCH}_{3} & \mathrm{Rha} & \mathbf{9} & \mathrm{OCH}_{3} & \mathrm{OCH}_{3} & \mathrm{Rha} & \mathrm{H} \\ \mathbf{1 0}^{*} & \mathrm{OH} & \mathrm{OCH}_{3} & \mathrm{Glu} & \mathbf{1 2} & \mathrm{H} & \mathrm{OCH}_{3} & \mathrm{Rha} & \mathrm{H} \\ \mathbf{1 1}^{*} & \mathrm{OH} & \mathrm{OCH}_{3} & \mathrm{Gal} & \mathbf{2 1} & \mathrm{OCH}_{3} & \mathrm{OCH}_{3} & \mathrm{Cou} & \mathrm{H} \\ \mathbf{1 3}^{*} & \mathrm{H} & \mathrm{OCH}_{3} & \mathrm{Gal} & \mathbf{2 3} & \mathrm{OH} & \mathrm{H} & \mathrm{Succ} & \mathrm{H} \\ \mathbf{1 4}^{\mathbf{1 5}} & \mathrm{OCH} & \mathrm{OCH}_{3} & \mathrm{Gal} & \mathbf{2 4} & \mathrm{H} & \mathrm{OCH} & \mathrm{Glu} & \mathrm{H} \\ \mathbf{1 6}^{*} & \mathrm{OH} & \mathrm{OH} & \mathrm{Ora} & \mathbf{2 5} & \mathrm{OH} & \mathrm{OH} & \mathrm{Cou}-\mathrm{rha} & \mathrm{Glu} \\ \mathbf{1 7}^{*} & \mathrm{H} & \mathrm{OCH}_{3} & \mathrm{Glu} & \mathbf{2 6} & \mathrm{OH} & \mathrm{OH} & \mathrm{Ac} & \mathrm{H} \\ \mathbf{1 8} & \mathrm{OCH} & \mathrm{OCH}_{3} & \mathrm{Glu} & \mathbf{2 7} & \mathrm{OH} & \mathrm{H} & \mathrm{Ac} & \mathrm{H} \\ & \mathrm{H} & \mathrm{OCH}_{3} & \mathrm{Ara} & \mathbf{2 8} & \mathrm{OH} & \mathrm{OCH}_{3} & \mathrm{Ac} & \mathrm{H} \\ & & & & \mathbf{2 9} & \mathrm{OCH} & \mathrm{OCH}_{3} & \mathrm{Ac} & \mathrm{H} \\ & & & & \mathbf{3 0} & \mathrm{OH}_{3} & \mathrm{OH}_{3} & \mathrm{Caff} & \mathrm{H} \\ & & & & \mathbf{3 1} & \mathrm{OCH}_{3} & \mathrm{OCH}_{3} & \mathrm{Ac} & \mathrm{H}\end{array}$

* Identified using standard compounds. Gal: Galactose; Glu: Glucose; Ara: Arabinose; Rha: Rhamnose; Cou: Coumaric; Succ: Succinic acid; Ac: Acetyl group; Caff: Caffeic acid.

Twenty three compounds were detected in blueberry (peaks 1-3, 6-15, 17, 19, 20, 22, 25-28, 30 and 31, Table 1) fourteen in calafate (peaks 3, 4, 7, 8, 10, 11, 15, 16-18, 21, 24, 28 and 29), nine in arrayán (peaks 2, 3, 7, 10, 14, 16, 17, 24 and 29), and six in meli (peaks 3, 6, 7, 10, 11 and 17), chequén (peaks 3, 5, 6, 7, 10 and 11) and murta (peaks 5, 8, 11, 16, 18 and 23). Figures S2 and S3 (Supplementary Material) show as examples full scan ToF-MS spectra of peaks 3, 8, 9, 10, 16, 17, 21, 22 and 28). Peaks 3, 6, 7, 10, 11, 13, 16 and 17 were identified by spiking experiments with authentic standards as delphinidin 3- $O$-galactoside (HR-MS ion at $m / z$ 465.1043, $\lambda_{\max }$ : 276-523), cyanidin-3-O-galactoside (HR-MS ion at $m / z$ 449.1052, $\lambda_{\max }: 280-511$ ), cyanidin-3-O-glucoside (HR-MS ion at $\mathrm{m} / z$ 449.1099, $\lambda_{\max }: 280-517$ ), petunidin-3-O-glucoside (HR-MS ion at $m / z 479.1233, \lambda_{\max }: 276-526$ ), petunidin-3- $O$ galactoside (HR-MS ion at $\mathrm{m} / \mathrm{z} 479.1233, \lambda_{\max }: 276-523$ ), peonidin-3-O-galactoside (HR-MS ion at $\mathrm{m} / \mathrm{z}$ $463.1234, \lambda_{\max }: 279-520$ ), peonidin-3-O-glucoside (HR-MS ion at $m / z 463.1258, \lambda_{\max }: 279-523$ ), and malvidin-3-O-glucoside (HR-MS ion at $m / z$ 493.1252, $\lambda_{\max }$ : 276-527), (Table 1), respectively. 
Table 1. Identification of phenolic compounds in chilean berries by LC-PDA-HR-ToF-ESI-MS data.

\begin{tabular}{|c|c|c|c|c|c|c|c|}
\hline $\begin{array}{c}\text { Peak } \\
\text { Number }\end{array}$ & $\begin{array}{c}\text { Retention } \\
\text { Time (min) }\end{array}$ & Uv max & $\begin{array}{c}\text { HR-M + ion } \\
(\text { ppm) }\end{array}$ & $\begin{array}{c}\text { Other ions } \\
\text { (Aglycon moiety) }\end{array}$ & Formula & Identification & Fruit \\
\hline 1 & 4.8 & $276-523$ & $641.1687(-4.8)$ & 317.0618 (Petunidin) & $\mathrm{C}_{28} \mathrm{H}_{33} \mathrm{O}_{17}$ & Petunidin-3-O-di-hexoside & blue \\
\hline 2 & 5.9 & $280-517$ & $611.1614(0.3)$ & 449.1709 (Cyanidin-3-O-hexoside) & $\mathrm{C}_{27} \mathrm{H}_{31} \mathrm{O}_{16}$ & Cyanidin- 3-O-di-hexoside & blue, arr \\
\hline 3 & 6.3 & $276-523$ & $465.1040(1.8)$ & 303.0500 (Delphinidin) & $\mathrm{C}_{21} \mathrm{H}_{21} \mathrm{O}_{12}$ & Delphinidin 3-O-galactoside * & blue, cal, che, arr, lu \\
\hline 4 & 6.8 & $276-525$ & $465.1038(1.1)$ & 303.0495(Delphinidin) & $\mathrm{C}_{21} \mathrm{H}_{21} \mathrm{O}_{12}$ & Delphinidin 3-O-glucoside * & cal \\
\hline 5 & 7.1 & $280-517$ & $595.1478(-31.0)$ & 449.1089 (Cyanidin-3-O-glucoside) & $\mathrm{C}_{27} \mathrm{H}_{31} \mathrm{O}_{15}$ & Cyanidin 3-O-rutinose & $\mathrm{mu}$ \\
\hline 6 & 7.8 & $280-511$ & $449.1052(-7.1)$ & 287.0675 (Cyanidin) & $\mathrm{C}_{21} \mathrm{H}_{21} \mathrm{O}_{11}$ & Cyanidin-3-O-galactoside * & blue, che, lu \\
\hline 7 & 9.1 & $280-517$ & $449.1099(3.3)$ & 287. 0507 (Cyanidin) & $\mathrm{C}_{21} \mathrm{H}_{21} \mathrm{O}_{11}$ & Cyanidin-3-O-glucoside $*$ & blue, che, lu \\
\hline 8 & 9.8 & $276-526$ & $625.1789(3.2)$ & 479.1198 (Petunidin-3-O-glucoside) & $\mathrm{C}_{28} \mathrm{H}_{33} \mathrm{O}_{16}$ & Petunidin-3-O-rutinoside & blue, cal, mu \\
\hline 9 & 10.7 & $276-527$ & $639.1911(-2.2)$ & 493.1136 (Malvidin-3-O-glucoside) & $\mathrm{C}_{29} \mathrm{H}_{35} \mathrm{O}_{16}$ & Malvidin-3-O-rutinose & blue \\
\hline 10 & 11.2 & $276-526$ & $479.1233(9.0)$ & 317.0672 (Petunidin) & $\mathrm{C}_{22} \mathrm{H}_{23} \mathrm{O}_{12}$ & Petunidin-3-O-glucoside * & blue, che, arr, lu \\
\hline 11 & 11.9 & $276-523$ & $479.1224(7.1)$ & 317.0646 (Petunidin) & $\mathrm{C}_{22} \mathrm{H}_{23} \mathrm{O}_{12}$ & Petunidin-3-O-galactoside * & blue, cal, mu, che, lu \\
\hline 12 & 12.5 & $276-525$ & $609.1825(0.8)$ & 301.0829 (Peonidin) & $\mathrm{C}_{28} \mathrm{H}_{33} \mathrm{O}_{15}$ & Peonidin 3-O-rutinose & blue \\
\hline 13 & 12.7 & $279-520$ & $463.1234(-1.3)$ & 301.0689 (Peonidin) & $\mathrm{C}_{22} \mathrm{H}_{23} \mathrm{O}_{11}$ & Peonidin-3-O-galactoside $*$ & blue \\
\hline 14 & 13.4 & $276-527$ & $493.1361(3.0)$ & 331.0832 (Malvidin) & $\mathrm{C}_{23} \mathrm{H}_{25} \mathrm{O}_{12}$ & Malvidin-3-O-galactoside * & blue, arr \\
\hline 15 & 14.0 & $276-523$ & $435.0936(2.1)$ & 303.0472 (Delphinidin) & $\mathrm{C}_{20} \mathrm{H}_{19} \mathrm{O}_{11}$ & Delphinidin-3-O-arabinoside & blue, cal \\
\hline 16 & 14.7 & $276-527$ & $463.1258(3.9)$ & 301.1257 (Peonidin) & $\mathrm{C}_{22} \mathrm{H}_{23} \mathrm{O}_{11}$ & Peonidin-3-O-glucoside & cal, mu, arr \\
\hline 17 & 15.3 & $276-527$ & $493.1252(-19.0)$ & 331.0789 (Malvidin) & $\mathrm{C}_{23} \mathrm{H}_{25} \mathrm{O}_{12}$ & Malvidin-3-O-glucoside * & blue, cal, arr, lu \\
\hline 18 & 15.6 & $279-527$ & $433.1131(-0.92)$ & 301.0709 (Peonidin) & $\mathrm{C}_{21} \mathrm{H}_{21} \mathrm{O}_{10}$ & Peonidin-3-O-arabinoside & $\mathrm{cal}, \mathrm{mu}$ \\
\hline 19 & 16.2 & $276-526$ & $449.1066(-4.0)$ & 317.1969 (Petunidin) & $\mathrm{C}_{21} \mathrm{H}_{21} \mathrm{O}_{11}$ & Petunidin-3-O-arabinoside & blue \\
\hline 20 & 16.7 & $280-517$ & $419.0978(-1.9)$ & 287. 0696 (Cyanidin) & $\mathrm{C}_{20} \mathrm{H}_{19} \mathrm{O}_{10}$ & Cyanidin-3-O-arabinoside $*$ & blue \\
\hline 21 & 17.3 & $276-311-527$ & $639.1933(34.2)$ & 493.1382 (Malvidin-3-O-glucoside) & $\mathrm{C}_{32} \mathrm{H}_{31} \mathrm{O}_{14}$ & Malvidin 3-O-(6" coumaroyl) glucoside & cal \\
\hline 22 & 17.8 & $276-527$ & $463.1284(9.5)$ & 330.1706 (Malvidin) & $\mathrm{C}_{22} \mathrm{H}_{23} \mathrm{O}_{11}$ & Malvidin-3-O-arabinose * & blue \\
\hline 23 & 18.0 & $280-517$ & $549.1639(7.1)$ & 449.1082 (Cyanidin-3-O-glucose) & $\mathrm{C}_{25} \mathrm{H}_{25} \mathrm{O}_{14}$ & Cyanidin-3-O-(6" succinoyl)-glucose & $\mathrm{mu}$ \\
\hline 24 & 18.6 & $279-523$ & $625.1820(8.2)$ & 463.0905 (Peonidin-3- $O$ - hexoside) & $\mathrm{C}_{28} \mathrm{H}_{33} \mathrm{O}_{16}$ & Peonidin 3-O-di hexoside & cal \\
\hline 25 & 19.4 & $276-311-523$ & $919.4460(2.1)$ & 303.0504 (Delphinidin) & $\mathrm{C}_{42} \mathrm{H}_{47} \mathrm{O}_{23}$ & $\begin{array}{l}\text { Delphinidin-3-O-rutinose } \\
\text { (6"-p-coumaroyl)-2"-O-glucose }\end{array}$ & blue \\
\hline 26 & 20.0 & $276-523$ & $507.1135(-0.4)$ & 303.0495 (Delphinidin) & $\mathrm{C}_{23} \mathrm{H}_{23} \mathrm{O}_{13}$ & Delphinidin 3-O-(6" acetyl) glucoside & blue \\
\hline 27 & 20.6 & $280-517$ & $491.1206(3.6)$ & 287.1232 (Cyanidin) & $\mathrm{C}_{23} \mathrm{H}_{23} \mathrm{O}_{12}$ & Cyanidin 3-O-(6" acetyl) glucoside & blue \\
\hline 28 & 21.4 & $276-526$ & $521.1293(-0.4)$ & 317.0676 (Petunidin) & $\mathrm{C}_{24} \mathrm{H}_{25} \mathrm{O}_{13}$ & Petunidin $3-O-(6 "$ acetyl $)$ glucoside & blue, cal \\
\hline 29 & 22.3 & $276-527$ & $535.1451(-0.2)$ & 331.0789 (Malvidin) & $\mathrm{C}_{25} \mathrm{H}_{27} \mathrm{O}_{13}$ & Malvidin 3-O-(6" acetyl) galactoside & cal, arr \\
\hline 30 & 23.2 & $276-321-523$ & $627.1393(-6.8)$ & 287.0743 (Cyanidin) & $\mathrm{C}_{30} \mathrm{H}_{27} \mathrm{O}_{15}$ & Delphinidin-3-O-(6"caffeoyl)-glucose & blue \\
\hline 31 & 24.0 & $276-527$ & $535.1463(1.5)$ & 331.0673 (Malvidin) & $\mathrm{C}_{25} \mathrm{H}_{27} \mathrm{O}_{13}$ & Malvidin 3-O-(6" acetyl) glucoside & blue \\
\hline
\end{tabular}


Peaks 4 and $\mathbf{1 4}$ were identified as the monoglucosides delphinidin 3-O-glucoside and malvidin-3-O-galactoside (HR-MS ions at $m / z 493.1361$ and 465.1038, respectively [19,26,27]. Peaks 1, 2 and 24 showing HR-MS molecular ions at $\mathrm{m} / \mathrm{z} 611.1614,641.1687$ and 625.1820 coincident with the formulas $\mathrm{C}_{27} \mathrm{H}_{31} \mathrm{O}_{16}(0.3), \mathrm{C}_{28} \mathrm{H}_{33} \mathrm{O}_{17}(-4.8)$ and $\mathrm{C}_{28} \mathrm{H}_{33} \mathrm{O}_{16}(8.2)$ were identified as petunidin $\left(\lambda_{\max }\right.$ : 276-523), cyanidin ( $\left.\lambda_{\max }: 280-517\right)$, and peonidin ( $\left.\lambda_{\max }: 279-523\right)$, dihexosides [12,28]. In a similar manner, peaks 5 (HR-MS at $m / z 595.1478, \mathrm{C}_{27} \mathrm{H}_{31} \mathrm{O}_{15},-31.0$ ), 8 (HR-MS at $m / z 625.1789, \mathrm{C}_{28} \mathrm{H}_{33} \mathrm{O}_{16}$, 3.2), 9 (HR-MS at $m / z 639.1911, \mathrm{C}_{29} \mathrm{H}_{35} \mathrm{O}_{16},-2.2$ ) and 12 (HR-MS at $m / z 609.1825, \mathrm{C}_{28} \mathrm{H}_{33} \mathrm{O}_{15}, 0.8$ ) were assigned as cyanidin, petunidin, malvidin and peonidin rutinosides [12,26,29,30]. Peaks 15, 18-20 and 22 (Figure 2) with HR-MS molecular ions at $m / z 435.0936\left(\mathrm{C}_{20} \mathrm{H}_{19} \mathrm{O}_{11}, 2.1\right), 433.1131\left(\mathrm{C}_{21} \mathrm{H}_{21} \mathrm{O}_{10},-0.92\right)$, $449.1066\left(\mathrm{C}_{21} \mathrm{H}_{21} \mathrm{O}_{11},-4.0\right), 419.0978\left(\mathrm{C}_{20} \mathrm{H}_{19} \mathrm{O}_{10},-1.9\right)$ and $463.1284\left(\mathrm{C}_{22} \mathrm{H}_{23} \mathrm{O}_{11}\right)$ were identified as delphinidin $\left(\lambda_{\max }: 276-523\right)$, peonidin $\left(\lambda_{\max }: 276-527\right)$, petunidin $\left(\lambda_{\max }: 276-523\right)$, cyanidin $\left(\lambda_{\max }\right.$ : 280-517) and malvidin ( $\left.\lambda_{\max }: 276-527\right)$ arabinosides, respectively [26,31], While peaks 21 (HR-MS at $m / z$ 639.1933, $\mathrm{C}_{32} \mathrm{H}_{31} \mathrm{O}_{14}$ ) and 23 (HR-MS at $m / z$ 549.1639, $\mathrm{C}_{25} \mathrm{H}_{25} \mathrm{O}_{14}$ ) were identified as malvidin 3-O-(6" coumaroyl) glucoside and cyanidin-3-O-(6" succinoyl)-glucose [28,30]. Peak 25 with a molecular ion at $m / z 919.4460\left(\mathrm{C}_{42} \mathrm{H}_{47} \mathrm{O}_{23}\right)$ present in blueberries was identified as the complex anthocyanin: delphinidin-3-O-rutinose (4"'-O-p-coumaroyl)-2"-O-glucose [27,32]. Peaks 26-28 and $\mathbf{3 1}$ with HR-MS peaks at $m / z 507.1135\left(\mathrm{C}_{23} \mathrm{H}_{23} \mathrm{O}_{13}\right), 491.1206\left(\mathrm{C}_{23} \mathrm{H}_{23} \mathrm{O}_{12}\right), 521.1293\left(\mathrm{C}_{24} \mathrm{H}_{25} \mathrm{O}_{13}\right)$, and 535.1463 $\left(\mathrm{C}_{24} \mathrm{H}_{25} \mathrm{O}_{13}\right)$, were identified as delphinidin, cyanidin, petunidin, and malvidin 3-O-(6" acetyl) glucosides as reported [27,31], while peak 30 (HR molecular ion at $\mathrm{m} / \mathrm{z} 627.1393$ coincident with a formula of $\mathrm{C}_{30} \mathrm{H}_{27} \mathrm{O}_{15}$ (-6.8) was identified as delphinidin-3-O-(6" caffeoyl)-glucose [29]. An isomer of peak 31 (peak 29, HR-MS ion at $m / z 535.1451\left(\mathrm{C}_{25} \mathrm{H}_{27} \mathrm{O}_{13},-0.2\right)$, was identified as malvidin 3-O-(6" acetyl) galactoside [27,31].

\subsection{Identification of Phenolic Acids and Flavonols}

Other minor phenolic compounds [12,15,33] were present in all six blueberries analyzed which were accurately identified (Figure 4). The phenolic acids: feruloyl-quinic acid (HR-ToF-MS: 369.1105, MF: $\mathrm{C}_{17} \mathrm{H}_{21} \mathrm{O}_{9},-0.3$ ), chlorogenic acid (HR-ToF-MS: 355.1061, MF: $\left.\mathrm{C}_{16} \mathrm{H}_{19} \mathrm{O}_{9}, 9.0\right)$ and neochlorogenic acid (HR-ToF-MS: 355.1038, molecular formula: $\mathrm{C}_{16} \mathrm{H}_{19} \mathrm{O}_{9}, 2.5$ ), the flavonols quercetin (HR-ToF-MS: 303.0489, MF: $\mathrm{C}_{15} \mathrm{H}_{11} \mathrm{O}_{7}$, error -5.3), myricetin (HR-ToF-MS: 319.0459 , molecular formula: $\mathrm{C}_{15} \mathrm{H}_{11} \mathrm{O}_{8}$, -1.6) rutin (HR-ToF-MS: 611.1614, MF: $\mathrm{C}_{27} \mathrm{H}_{31} \mathrm{O}_{16}, 0.3$ ) hyperoside (HR-ToF-MS: 465.1043, MF: $\mathrm{C}_{21} \mathrm{H}_{21} \mathrm{O}_{12}$, 2.2) isoquercitrin (HR-ToF-MS: 465.1032, MF: $\mathrm{C}_{21} \mathrm{H}_{21} \mathrm{O}_{12},-0.2$ ) and isorhamnetin (HR-ToF-MS: $317.0670, \mathrm{MF}: \mathrm{C}_{16} \mathrm{H}_{13} \mathrm{O}_{7}, 2.8$; this last flavonoid was only present in chequén fruits).

\subsection{Total Phenolics, Flavonoids and Anthocyanin Contents}

The total phenolic content (TPC) varied from $5.11 \pm 0.18$ for chequén to $65.53 \pm 1.35 \mu \mathrm{M}$ Trolox equivalents/g DW for calafate fruits, and showed linear correlation with the antioxidant assays $\left(\mathrm{R}^{2}=0.8755\right.$ and $\mathrm{R}^{2}=0.9143$ for TPC/DPPH and TPC/FRAP assays, respectively, Table 2$)$ the TPC of our sample of calafate showed values two times higher than a Chilean sample from Mañihuales [11] but was close to that reported for a Chilean sample from Faro San Isidro [12]. The total anthocyanin content (TAC) ranged from $1.54 \pm 0.05$ for chequén to $51.62 \pm 1.78 \mathrm{mg}$ cyanidin-3-glucoside/g DW for calafate and showed strong linear correlation with the antioxidant assays $\left(R^{2}=0.7044\right.$ and $R^{2}=0.9914$ 
for TAC/DPPH and TAC/FRAP assays, respectively, Table 2). The total flavonoid content (TFC) showed similar trend, varying from $2.57 \pm 0.11$ for $L$. chequén to $45.72 \pm 2.68 \mathrm{mg}$ quercetin $/ \mathrm{g}$ DW for Berberis microphylla. The TFC showed linear correlation with the antioxidant assays $\left(\mathrm{R}^{2}=0.678\right.$ for TFC/DPPH and $\mathrm{R}^{2}=0.9856$ for TFC/FRAP assays, respectively. The total anthocyanin content for our sample of calafate was close to the values reported for Chilean samples collected in La Junta and Darwin (16.76 mmol/g fresh weigh) and Faro San Isidro (15.44 mmol/g fresh weigh) taking into account conversion factors and 85\% water loss (approximately 50.11 and $46.21 \mathrm{mg} / \mathrm{g}$ dry weight, respectively) [12]. The levels of anthocyanins in the fruits can explain the different intensity in the color especially for murta, which is red-rose, in comparison with calafate which is purple and blueberry and arrayán which are black (Figure 1).

Table 2. Scavenging of the 1,1-diphenyl-2-picrylhydrazyl Radical (DPPH), Ferric Reducing Antioxidant Power (FRAP), Superoxide Anion scavenging activity (SA), Total Phenolic Content (TPC), Total Flavonoid Content (TFC), Total Anthocyanin Content (TAC), and Extraction Yields of Six Edible Berry Fruits From the VIII Region of Chile.

\begin{tabular}{|c|c|c|c|c|c|c|c|}
\hline Species & DPPH $^{a}$ & $\operatorname{FRAP}^{\boldsymbol{\beta}}$ & $\mathbf{S A}^{\circ}$ & $\mathbf{T P C}^{\delta}$ & TFC $^{\psi}$ & $\operatorname{TAC}^{\chi}$ & $\begin{array}{c}\text { Extraction } \\
\text { Yields (\%) }{ }^{\mu}\end{array}$ \\
\hline $\begin{array}{l}\text { Vaccinium } \\
\text { corymbosum }\end{array}$ & $3.32 \pm 0.18 a$ & $96.15 \pm 5.39 d f$ & $72.61 \pm 1.91 r$ & $45.86 \pm 3.46$ & $18.50 \pm 3.75 p$ & $21.41 \pm 1.65$ & 6.72 \\
\hline $\begin{array}{l}\text { Berberis } \\
\text { microphylla }\end{array}$ & $2.33 \pm 0.21 a b$ & $124.46 \pm 6.54$ & $81.31 \pm 2.95 s$ & $65.53 \pm 1.35$ & $45.72 \pm 2.68$ & $51.62 \pm 1.78$ & 4.99 \\
\hline Luma chequén & $12.92 \pm 0.30$ & $76.22 \pm 3.45 e$ & $43.79 \pm 2.91 t$ & $5.11 \pm 0.18 k$ & $2.57 \pm 0.11 \mathrm{~m}$ & $1.54 \pm 0.05$ & 7.39 \\
\hline Luma apiculata & $5.88 \pm 0.21$ & $93.4 \pm 4.68 d g$ & $64.22 \pm 3.46$ & $27.61 \pm 1.61$ & $12.80 \pm 2.43 n p$ & $15.24 \pm 1.49 l$ & 6.34 \\
\hline Ugni molinae & $10.94 \pm 0.32 c$ & $81.10 \pm 4.58$ ehj & $52.22 \pm 1.81 t$ & $9.24 \pm 0.28 k$ & $5.54 \pm 0.91 \mathrm{mo}$ & $6.85 \pm 0.10$ & 5.21 \\
\hline Amomyrtus meli & $7.46 \pm 0.10 b$ & $88.29 \pm 6.34 f g h i$ & $56.44 \pm 2.32$ & $17.52 \pm 0.66$ & $11.76 \pm 2.04$ no & $13.33 \pm 2.69 l$ & 4.89 \\
\hline Gallic acid $^{\phi}$ & $\begin{array}{c}1.36 \pm 0.22 \\
(7.99 \pm 1.29 \mu \mathrm{M})\end{array}$ & $148.1 \pm 8.35$ & $94.39 \pm 1.98$ & - & - & - & - \\
\hline $\begin{array}{l}\text { Cyanidin } \\
\text { 3-O-glucoside }{ }^{\phi}\end{array}$ & $\begin{array}{c}8.47 \pm 1.23 c \\
(17.47 \pm 2.53 \mu \mathrm{M})\end{array}$ & $95.48 \pm 6.72 i j$ & $76.85 \pm 1.71 r s$ & - & - & - & - \\
\hline
\end{tabular}

${ }^{\boldsymbol{\alpha}}$ Antiradical DPPH activities are expressed as $\mathrm{IC}_{50}$ in $\mu \mathrm{g} / \mathrm{mL}$ for extracts and compounds. ${ }^{\boldsymbol{\beta}}$ Expressed as $\mu \mathrm{M}$ trolox equivalents/g dry weight. ${ }^{\circ}$ Expressed in percentage scavenging of superoxide anion at $100 \mu \mathrm{g} / \mathrm{mL}$. $\delta$ Total phenolic content (TPC) expressed as mg gallic acid/g dry weight. ${ }^{\psi}$ Total flavonoid content (TFC) expressed as mg quercetin/g dry weight. ${ }^{\chi}$ Total Anthocyanin content (TAC) expressed as mg cyanidin 3-O-glucoside/g dry weight. ${ }^{\mu}$ Extraction yields expressed in percent W/W extraction on the basis of freeze dried material. ${ }^{\phi}$ Used as standard antioxidants. Values in the same column marked with the same letter are not significantly different (at $p<0.05$ ).

\subsection{Quantification of Individual Anthocyanins}

The major anthocyanins were quantified in the six edible berries, for some of the species for the first time. The order for the sum of the major anthocyanins was: calafate $>$ blueberries $>$ arrayan $>$ meli $>$ murtilla $>$ chequen (Table 3 ) which is coincident with the trend found for the total anthocyanin content (TAC) (Table 2) measured by a colorimetric method. The HPLC quantification method showed good performance, baseline was good (Figure 2), and the correlation coefficients for the standard curves of the 
glycosilated standard anthocyanins varied from 0.998 to 0.999 . The limits of detection for three representative compounds were 0.08 to $0.12 \mu \mathrm{g} / \mathrm{mL}$ and the limits of quantification were 0.24 to $0.35 \mu \mathrm{g} / \mathrm{mL}$ (Table 4). Repeatability for retention time and peak area was good, relative standard deviations were below 2.00\% [34]. As seen in Table 4 all recovery results varied from $97.93 \pm 0.33$ to $99.72 \pm 1.34$ and were within the usually required recovery range of $100 \% \pm 5 \%$ [34]. However, the anthocyanin concentration in our Chilean blueberries sample is quite different from those published for blueberries from other locations [31,35] being the major anthocyanins found peonidin-3-O-arabinoside and delphinidin-3- $O$-arabinoside ( $37.43 \pm 4.76$ and $34.43 \pm 3.28 \mathrm{mg} / 100 \mathrm{~g}$ fresh weight, respectively) followed by malvidin-3-O-glucoside and petunidin-3-O-rutinoside (Table 3 ). In the case of calafate (Berberis microphylla) the major anthocyanins were delphinidin 3-O-galactoside, petunidin-3-O-glucoside and malvidin-3-O-glucoside $(60.42 \pm 1.28,51.39 \pm 1.65$ and $42.94 \pm 1.25, \mathrm{mg} / 100 \mathrm{~g}$ fresh weight, respectively). We found as the major anthocyanin in this species delphinidin 3-O-galactoside, but Ruiz et al [15] reported delphinidin 3-O-glucoside as the major constituent $(8.83 \pm 1.53 \mu \mathrm{mol} / \mathrm{g}$ fresh weight), followed by petunidin-3-glucoside $(4.71 \pm 1.08 \mu \mathrm{mol} / \mathrm{g}$ fresh weight). For chequén (Luma chequen) the main anthocyanins were cyanidin-3-O-galactoside, petunidin-3-O-glucoside and petunidin-3-O-galactoside $(43.46 \pm 1.39,12.83 \pm 1.65$ and $9.55 \pm 1.02 \mathrm{mg} / 100 \mathrm{~g}$ fresh weight, respectively), and for arrayán (Luma apiculata) were petunidin-3-O-glucoside, malvidin-3-O-glucoside, delphinidin 3-O-galactoside and cyanidin-3-O-glucoside $(48.21 \pm 2.2,44.75 \pm 3.31,34.43 \pm 2.12$ and $9.45 \pm 0.15 \mathrm{mg} / 100 \mathrm{~g}$ fresh weight, respectively). Our sample of murtilla (Ugni molinae) showed two main anthocyanins (petunidin-3-O-rutinoside and peonidin-3-O-glucoside, Figure 2, Tables 1 and 3) and meli (Amomyrtus meli) showed six main glycosilated anthocyanins including cyanidin-3-O-galactoside and petunidin-3-O-galactoside as major ones (Tables 1 and 3). These compounds were quantified in these Luma species for the first time.

\subsection{Antioxidant Features}

The order of the antioxidant activity measured by the bleaching of the radical DPPH and the ferric reducing antioxidant power (FRAP) showed by the six fruits was calafate $>$ blueberry $>$ arrayán $>$ meli $>$ murta $>$ chequén which is also the order found for the sum of the individual major anthocyanins measured by HPLC. A similar trend was observed for superoxide anion scavenging activity (Table 2, Figure S1, Supplementary Material). Calafate showed the highest antioxidant activity $(2.33 \pm 0.21 \mu \mathrm{g} / \mathrm{mL}$ and $124.46 \pm 6.54 \mu \mathrm{M}$ TE/g dry weight in the DPPH and FRAP assays, respectively, Table 2), followed by blueberry $(3.32 \pm 0.18 \mu \mathrm{g} / \mathrm{mL}$ and $96.15 \pm 5.39 \mu \mathrm{M} \mathrm{TE} / \mathrm{g} \mathrm{DW})$, and arrayán $(5.88 \pm 0.21$ and $93.4 \pm 4.68 \mu \mathrm{M}$ TE/g DW, Table 2). The bleaching of the radical DPPH for calafate was close to that shown by the standards gallic acid and cyanidin-3-glucoside $(1.36 \pm 0.22$ and $8.47 \pm 1.23 \mu \mathrm{g} / \mathrm{mL}$, respectively). The antioxidant activities showed positive correlation with polyphenolic content assays $\left(0.67 \geq \mathrm{R}^{2} \geq 0.9856\right)$. It is reported that fruits antioxidant activities and composition of phenolics are dependent of genetic differences among different species and environmental conditions and harvest and/or ripeness within the same species [11,36] which can explain the differences in phenolic composition and antioxidant capacities found between the species under study and among other reports of antioxidant activities and phenolic composition of the same species from other zones of Chile $[11,12,15]$. 
Figure 4. Full scan ToF MS spectra and structures of minor phenolic compounds detected in six berries from the VIII region of Chile. (a) Hyperoside, (b) feruloyl-quinic acid, (c) chlorogenic acid (d) isoquercitrin (e) quercetin, (f) neochlorogenic acid (g) rutin (h) isorhamnetin and (i) myricetin.

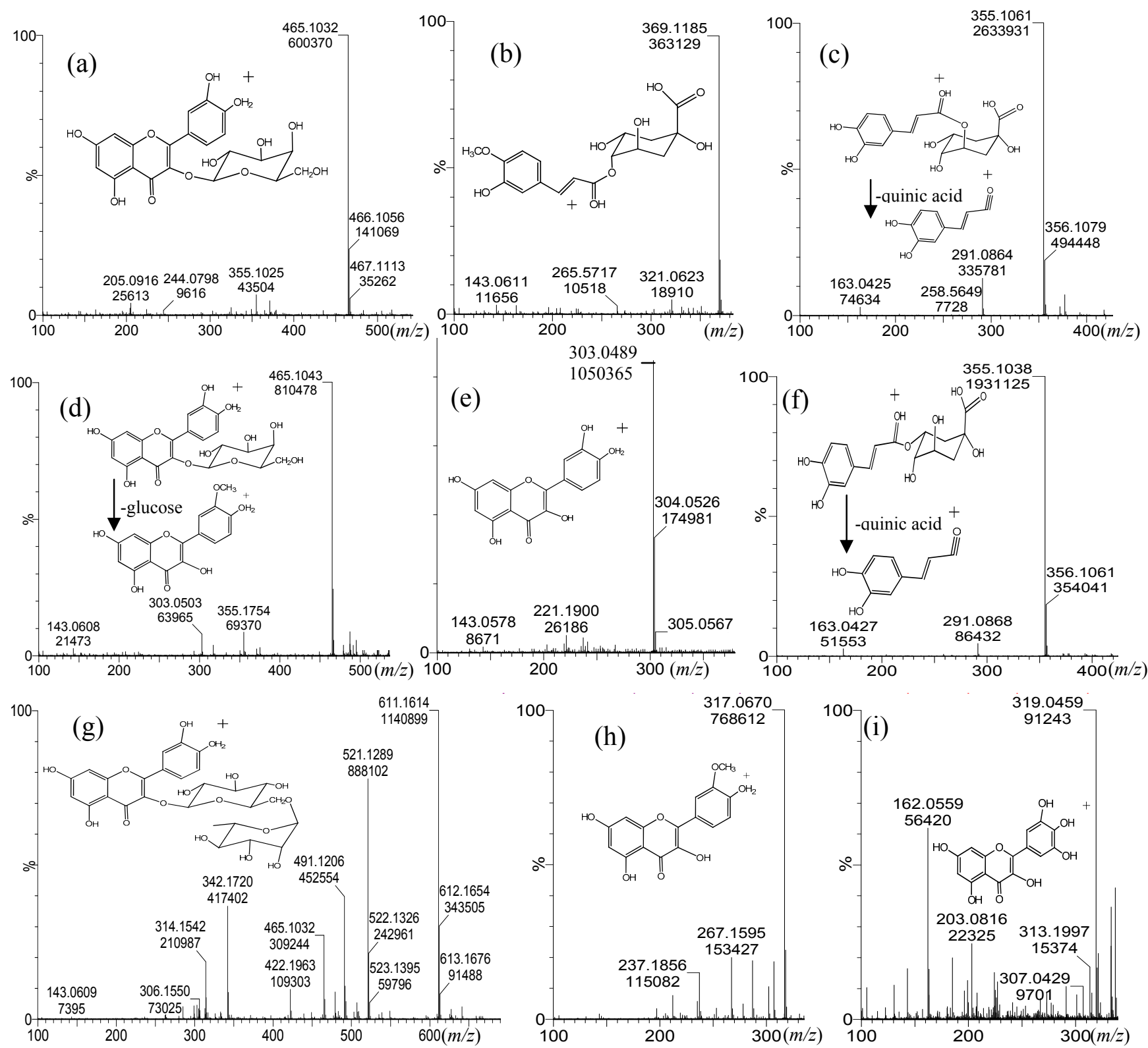


Table 3. Major anthocyanins quantified by HPLC-DAD in six edible berry fruits from the VIII Region of Chile.

\begin{tabular}{|c|c|c|c|c|c|c|c|c|c|c|c|c|c|c|}
\hline \multicolumn{15}{|c|}{ Anthocyanin $(\mathrm{mg} / 100 \mathrm{~g})^{\mathrm{a}}$} \\
\hline Berry Species & 2 & 3 & 6 & 7 & 8 & 10 & 11 & 13 & 15 & 16 & 17 & 18 & 20 & Total \\
\hline Vaccinium corymbosum & $19.23 \pm 3.18$ & $8.51 \pm 3.29 \mathrm{a}$ & $21.17 \pm 0.32$ & $0.96 \pm 0.12$ & $14.29 \pm 2.15$ & $9.27 \pm 2.22 \mathrm{~d}$ & $1.78 \pm 0.01$ & $14.28 \pm 0.98$ & $34.43 \pm 3.28$ & nd & $16.42 \pm 1.45$ & nd & $37.43 \pm 4.76$ & 177.77 \\
\hline Berberis microphylla & nd & $60.42 \pm 1.28$ & nd & $21.89 \pm 2.74 \mathrm{~b}$ & nd & $51.39 \pm 1.65 \mathrm{e}$ & $6.45 \pm 0.89$ & nd & $9.28 \pm 0.01$ & $3.96 \pm 0.02$ & $42.94 \pm 1.25 \mathrm{f}$ & $3.84 \pm 0.02$ & nd & 200.17 \\
\hline Luma chequén & nd & $3.72 \pm 0.02$ & $43.46 \pm 1.39$ & $5.29 \pm 0.23$ & nd & $12.83 \pm 1.65$ & $9.55 \pm 1.02$ & nd & nd & nd & nd & nd & nd & 74.85 \\
\hline Luma apiculata & $2.6 \pm 0.01$ & $34.43 \pm 2.12$ & nd & $9.45 \pm 0.15$ & nd & $48.21 \pm 2.2 \mathrm{e}$ & nd & nd & nd & nd & $44.75 \pm 3.31 \mathrm{f}$ & nd & nd & 139.44 \\
\hline Ugni molinae & nd & nd & nd & nd & $51.37 \pm 0.28$ & nd & $4.87 \pm 0.02$ & nd & nd & $61.48 \pm 2.42$ & nd & $4.43 \pm 0.04$ & nd & 122.15 \\
\hline Amomyrtus meli & nd & $8.87 \pm 1.76 \mathrm{a}$ & $48.39 \pm 2.23$ & $20.43 \pm 2.39 \mathrm{~b}$ & & $13.54 \pm 2.46 \mathrm{~d}$ & $27.12 \pm 1.25$ & nd & nd & nd & $8.45 \pm 1.13$ & nd & nd & 126.80 \\
\hline
\end{tabular}

${ }^{\mathrm{a}}$ Expressed as $\mathrm{mg} / 100 \mathrm{~g}$ fresh weight, measurements are expressed as mean $\pm \mathrm{SD}$ of five parallel determinations. (Values in the same row marked with the same letter are not significantly different at $p<0.05)$. nd: not detected/determined.

Table 4. Inter-day and Intra-day accuracy and precision (as RSD\%), limits of detection (LOD) and quantification (LOQ) and recovery of three major anthocyanins (compounds $\mathbf{3}, \mathbf{7}$ and 10).

\begin{tabular}{|c|c|c|c|c|c|c|c|c|c|}
\hline & & Inter day & & & Intra day & & & & \\
\hline Compound & $\begin{array}{c}\text { Nominal } \\
\text { concentration } \\
(\mu \mathrm{g} / \mathrm{mL}) \\
\end{array}$ & $\begin{array}{c}\text { Observed } \\
\text { concentration } \\
(\mu \mathrm{g} / \mathrm{mL}) \\
\end{array}$ & $\begin{array}{c}\text { Accuracy } \\
(\%)\end{array}$ & RSD\% & $\begin{array}{c}\text { Observed } \\
\text { concentration } \\
(\mu \mathrm{g} / \mathrm{mL}) \\
\end{array}$ & Accuracy (\%) & RSD\% & $\begin{array}{l}\text { LOD-LOQ } \\
\quad(\mu \mathrm{g} / \mathrm{mL})\end{array}$ & $\begin{array}{c}\text { Sample- } \\
\text { Recovery } \\
(\text { mean } \pm \text { RSD\% ) }\end{array}$ \\
\hline 3 & 10 & $10.94 \pm 0.05$ & 109.45 & 0.071 & $11.83 \pm 0.05$ & 118.33 & 0.04 & $0.08-0.24$ & Calafate $97.93 \pm 0.33$ \\
\hline 3 & 20 & $20.91 \pm 0.62$ & 104.55 & 0.80 & $21.73 \pm 0.37$ & 108.66 & 0.34 & & Arrayán $98.73 \pm 1.50$ \\
\hline 3 & 40 & $40.49 \pm 0.70$ & 101.23 & 0.69 & $41.2 \pm 0.72$ & 103.00 & 0.70 & & Blueberry $98.57 \pm 0.33$ \\
\hline 7 & 10 & $12.0 \pm 0.08$ & 120.00 & 0.08 & $12.13 \pm 0.15$ & 121.33 & 0.12 & $0.12-0.35$ & Calafate $99.72 \pm 1.34$ \\
\hline 7 & 20 & $19.81 \pm 0.27$ & 99.08 & 0.28 & $20.36 \pm 0.76$ & 101.80 & 0.75 & & Arrayán $98.97 \pm 1.98$ \\
\hline 7 & 40 & $40.77 \pm 0.37$ & 101.93 & 0.36 & $40.46 \pm 0.67$ & 101.15 & 0.66 & & Chequén $99.84 \pm 0.16$ \\
\hline 10 & 10 & $10.56 \pm 0.81$ & 105.66 & 0.77 & $9.99 \pm 0.12$ & 99.96 & 0.12 & $0.09-0.30$ & Calafate $99.31 \pm 0.35$ \\
\hline 10 & 20 & $20.20 \pm 0.59$ & 101.03 & 0.58 & $20.61 \pm 0.33$ & 103.05 & 0.32 & & Arrayán $98.59 \pm 0.38$ \\
\hline 10 & 40 & $41.04 \pm 0.41$ & 102.64 & 0.40 & $40.8 \pm 0.36$ & 40.8 & 0.79 & & Chequén $98.19 \pm 0.76$ \\
\hline
\end{tabular}




\section{Experimental}

\subsection{Chemicals and Plant Material}

Folin-Ciocalteu phenol reagent $(2 \mathrm{~N})$, reagent grade $\mathrm{Na}_{2} \mathrm{CO}_{3}, \mathrm{AlCl}_{3}, \mathrm{HCl}, \mathrm{FeCl}_{3}, \mathrm{NaNO}_{2}, \mathrm{NaOH}$, quercetin, trichloroacetic acid, sodium acetate, HPLC-grade water, HPLC-grade acetonitrile, reagent grade $\mathrm{MeOH}$ and formic acid were obtained from Merck (Darmstadt, Germany) Cyanidin, delphinidin 3-O-galactoside, cyanidin-3-O-galactoside, cyanidin-3-O-glucoside, petunidin-3-O-glucoside, petunidin-3-O-galactoside, peonidin-3-O-galactoside, peonidin-3- $O$-glucoside and malvidin-3-O-glucoside (all standards with purity higher than $95 \%$ by HPLC) were purchased either from ChromaDex (Santa Ana, CA, USA), Extrasynthèse (Genay, France) or Wuxi Apptec Co. Ltd. (Shangai, China). Gallic acid, TPTZ (2,4,6- tri(2-pyridyl)-s-triazine), Trolox, tert-butylhydroperoxide, nitro blue tetrazolium, xanthine oxidase and DPPH (1,1-diphenyl-2-picrylhydrazyl radical) were purchased from Sigma-Aldrich Chemical Co. (St. Louis, MO, USA). All ripe fruits for this study (aprox. $500 \mathrm{~g}$ each) were collected at Región del Bio-Bio, Chile. Sampling was performed using sterile disposable gloves and rigid plastic sample containers and each sample was submitted individually by overnight courier to our laboratory in Antofagasta to prevent deterioration. This sampling methodology was previously used for other edible fruits $[19,23,33]$. Random healthy ripe fruits, representative of the lot, were collected from various specimens (at least 10 fruits per specimen) and different locations (at least 3) in each growing area. Ripe fruits of arrayán (L. apiculata (DC.) burret, chequén (L. chequén (Molina) A. Gray), and murta (U. molinae Turcz) were collected in Re-Re, Chile in May 2011. Meli (A. meli (Phil.) D. Legrand \& Kausel and calafate (B. microphylla G. Forst) were collected in the Andean woods of Santa Bárbara, in May 2011. Blueberries (V. corymbosum) variety highbush Brigitta were collected in April 2011 in the area of Chillán. Voucher herbarium specimens including samples of fruits were deposited at the Laboratorio de Productos Naturales, Universidad de Antofagasta, Antofagasta, Chile, with the numbers La-111505-1, Lc-111505-2, Um-111505-1, Am-111805-1, Bm-111805-1 and Vc-110704-1, respectively.

\subsection{Sample Preparation}

Fresh fruits (Figures S4-S9, supplementary material) were carefully washed, separately homogenized in a blender and freeze-dried (Labconco Freezone 4.5 L, Kansas, MO, USA). Ten grams of each lyophilized fruit was finally pulverized in a mortar, defatted thrice with $100 \mathrm{~mL}$ of $\mathrm{n}$-hexane and then extracted with $100 \mathrm{~mL}$ of $0.1 \% \mathrm{HCl}$ in $\mathrm{MeOH}$ in the dark in an ultrasonic bath for one hour each time, The extracts were combined, filtered and evaporated in vacuo in the dark $\left(40{ }^{\circ} \mathrm{C}\right)$. The extracts were suspended in $20 \mathrm{~mL}$ ultrapure water and loaded onto an XAD-7 (100 g) column. The column was rinsed with water $(100 \mathrm{~mL})$ and phenolic compounds were eluted with $100 \mathrm{~mL}$ of $\mathrm{MeOH}$ acidified with $0.1 \% \mathrm{HCl}$. This methodology was previously used for other edible fruits $[19,23,33]$. The solutions were combined and evaporated to dryness under reduced pressure $\left(40{ }^{\circ} \mathrm{C}\right)$ to give $634.20,739.20,499.93$, $672.24,489.93$ and $521.38 \mathrm{mg}$ of L. apiculata, L. chequén, B. microphylla, V. corymbosum, A. meli and U. molinae fruits, respectively. 


\subsection{Liquid Chromatography Analysis}

A portion of each extract (approximately $2 \mathrm{mg}$ ) obtained as explained above was dissolved in $2 \mathrm{~mL}$ $0.1 \% \mathrm{HCl}$ in $\mathrm{MeOH}$, filtered through a $0.45 \mu \mathrm{m}$ micropore membrane (PTFE, Waters, Milford, MA, USA) before use and was injected into the HPLC-PDA and ESI-ToF-MS equipment. Qualitative HPLC-PDA analysis of the extracts was performed using a Waters Alliance 2695 system equipped with 2695 separation module unit and 2996 PDA detector and a $250 \times 4.6 \mathrm{~mm}, 5 \mu \mathrm{m}, 100 \AA$, Luna C-18 column (Phenomenex, Torrance, CA, USA), with a linear gradient solvent system of $0.1 \%$ aqueous formic acid (solvent $\mathrm{A}$ ) and acetonitrile $0.1 \%$ formic acid (solvent $\mathrm{B}$ ) as follows: $90 \%$ solvent A until 4 min, followed by $90 \%-75 \%$ solvent A over $25 \mathrm{~min}$, then $75 \%-10 \%$ A over 35 min, then going back to $90 \%$ solvent A until $45 \mathrm{~min}$. and finally reconditioning the column with $90 \%$ solvent A isocratic for 15 min. The flow rate and the injection volume were $0.5 \mathrm{~mL} / \mathrm{min}$ and $20 \mu \mathrm{L}$, respectively. The compounds were monitored using a wavelength range of $210-800 \mathrm{~nm}$.

\subsection{Validation of the HPLC Method}

Quantification was done by external standardization, using the respective standard anthocyanins, at the wavelengths of maximum absorption of the compounds. For the validation of the analytical method based on HPLC factors, linearity, precision, detection limits and accuracy were evaluated following [34]. Stock solutions of all seven standard compounds $(\mathbf{3}, 4,6,7,10,11$, and 17) were prepared by dissolving one milligram of each anthocyanin in methanol-formic acid $1 \%(1 \mathrm{mg} / \mathrm{mL})$. Several calibration levels were prepared by diluting the stock solutions with methanol-formic acid $1 \%$ yielding concentrations of $15.65,31.25,62.5,125,250$ and $500 \mu \mathrm{g} / \mathrm{mL}$. The calibration curves $\left(\mathrm{R}^{2}>0.098\right)$ were obtained by plotting peak areas versus concentrations. Compound 15 was quantified using the calibration curve obtained for $\mathbf{3}$, compounds 15-18 and 20 with the calibration curve of 11 and compound $\mathbf{2}$ with the calibration curve of compound 7. Limits of detection (LOD) and quantitation (LOQ) were measured for three representative compouns (3, 7 and 10, Table 4) and are reported as the concentrations that gave signal-to-noise ratios of 3 and 10, respectively, from three replicate injections. Accuracy was determined by spiking three standard anthocyanins (3, 7 and 10, Table 4) at three concentration levels (10: low, 20: medium, and $40 \mu \mathrm{g} / \mathrm{mL}$ : high spike) in one gram of each fresh fruits, which was then extracted and assayed as described before. Mean percentage recovery in relation to the theoretically present amounts $(\%$ recovery $=$ amount detected $\times 100 /$ theoretical amount $)$ were used as a measure of accuracy (Table 4$)$. The relative standard deviation (RSD\%) within the measurements was considered as a measure of precision and repeatability. The samples were prepared and analyzed for anthocyanin concentration on the same day and on three consecutive days $(n=5)$ for intra- and interday precision respectively.

\subsection{Mass Spectrometric Conditions}

Hyphenated PDA with high-resolution electrospray ionization-time of flight-mass spectrometry (HR-ESI-ToF-MS) analysis was performed using a LCT premier XE ToF mass spectrometer (Waters) equipped with an ESI interface and controlled by MassLynx V4.1 software, using the chromatographic conditions as stated above. The compounds were monitored using PDA with a wavelength range of 210-800 nm, while mass spectra were acquired with electrospray ionization and the ToF mass analyzer 
in both positive and negative modes over the range $\mathrm{m} / \mathrm{z}$ : 100-1000. The capillary voltages were set at $3000 \mathrm{~V}$ (positive mode) and $2800 \mathrm{~V}$ (negative mode), respectively, and the cone voltage was $20 \mathrm{~V}$. Nitrogen was used as the nebulizer and desolvation gas. The desolvation and cone gas flow rates were 300 and $20 \mathrm{~L} / \mathrm{h}$, respectively. The desolvation temperature was $400{ }^{\circ} \mathrm{C}$, and the source temperature was $120^{\circ} \mathrm{C}$. For the dynamic range enhancement (DRE) lockmass, a solution of leucine enkephalin (Sigma-Aldrich, Steinheim, Germany) was infused by a secondary reference probe at $200 \mathrm{pg} / \mathrm{mL}$ in $\mathrm{CH}_{3} \mathrm{CN} /$ water (1:1) containing $0.1 \%$ formic acid with the help of a second LC pump (Waters 515 HPLC pump). The reference mass was scanned once every five scans for each positive and negative data collection. Both positive and negative ESI data were collected using a scan time of $0.2 \mathrm{~s}$, with an interscan time of $0.01 \mathrm{~s}$, and a polarity switch time of $0.3 \mathrm{~s}$. The full chromatograms were recorded at two different aperture voltages. The most intense fragmental ions and molecular ions could be obtained, when the aperture voltage were set at $60 \mathrm{~V}$ and $0 \mathrm{~V}$, respectively. V-optics mode was used for increased intensity.

\subsection{Antioxidant Assays}

\subsubsection{Free Radical Scavenging Capacity}

The free radical scavenging capacity of the extracts was determined by the DPPH assay as previously described [37], with some modifications. DPPH radical absorbs at $517 \mathrm{~nm}$, but upon reduction by an antioxidant compound its absorption decreases. Briefly, $50 \mu \mathrm{L}$ of processed SPE MeOH extract or pure compound prepared at different concentrations was added to $2 \mathrm{~mL}$ of fresh $0.1 \mathrm{mM}$ solution of DPPH in methanol and allowed to react at $37^{\circ} \mathrm{C}$ in the dark. After thirty minutes the absorbance was measured at $517 \mathrm{~nm}$. The DPPH scavenging ability as percentage was calculated as: DPPH scavenging ability $=\left(\mathrm{A}_{\text {control }}-\mathrm{A}_{\text {sample }} / \mathrm{A}_{\text {control }}\right) \times 100$. Afterwards, a curve of \% DPPH bleaching activity versus concentration was plotted and $\mathrm{IC}_{50}$ values were calculated. $\mathrm{IC}_{50}$ denotes the concentration of sample required to scavenge $50 \%$ of $\mathrm{DPPH}$ free radicals. The lower the $\mathrm{IC}_{50}$ value the more powerful the antioxidant activity. Gallic acid (from 1.0 to $125.0 \mu \mathrm{g} / \mathrm{mL}, \mathrm{R}^{2}=0.991$ ) and cyanidin 3-O-glucoside (from 1.0 to $125.0 \mu \mathrm{g} / \mathrm{mL}, \mathrm{R}^{2}=0.997$ ) were used as standard antioxidant compounds.

\subsubsection{Ferric Reducing Antioxidant Power}

The determination of ferric reducing antioxidant power or ferric reducing ability (FRAP assay) of the extracts was performed as described by [38] with some modifications. The stock solutions prepared were $300 \mathrm{mM}$ acetate buffer pH 3.6, $10 \mathrm{mM}$ TPTZ (2,4,6-tri(2-pyridyl)-s-triazine) solution in $40 \mathrm{mM} \mathrm{HCl}$, and $20 \mathrm{mM} \mathrm{FeCl} \cdot 6 \mathrm{H}_{2} \mathrm{O}$ solution. Plant extracts or standard methanolic Trolox solutions $(150 \mu \mathrm{L})$ were incubated at $37{ }^{\circ} \mathrm{C}$ with $2 \mathrm{~mL}$ of the FRAP solution (prepared by mixing $25 \mathrm{~mL}$ acetate buffer, $5 \mathrm{~mL}$ TPTZ solution, and $10 \mathrm{~mL} \mathrm{FeCl} \cdot 6 \mathrm{H}_{2} \mathrm{O}$ solution) for $30 \mathrm{~min}$ in the dark. Absorbance of the blue ferrous tripyridyltriazine complex formed was then read at $593 \mathrm{~nm}$. Quantification was performed using a standard calibration curve of the antioxidant Trolox (from 0.2 to $2.5 \mu \mathrm{mol} / \mathrm{mL}, \mathrm{R}^{2}$ : 0.995 ). Samples were analyzed in triplicate and results are expressed in $\mu \mathrm{mol} \mathrm{TE} / \mathrm{gram}$ dry mass. 


\subsubsection{Superoxide Anion Scavenging Activity}

The enzyme xanthine oxidase is able to generate superoxide anion radical $\left(\mathrm{O}_{2}{ }^{-{ }^{-}}\right)$"in vivo" by oxidation of reduced products from intracellular ATP metabolism. The superoxide anion generated in this reaction sequence reduces the nitro blue tetrazolium dye (NBT), leading to a chromophore with a maximum of absorption at $560 \mathrm{~nm}$. Superoxide anion scavengers reduce the speed of generation of the chromophore. The superoxide anion scavenging activities of isolated compounds and fractions were measured spectrophotometrically in a microplate reader as reported previously [23]. All compounds, and berry extracts were evaluated at $100 \mu \mathrm{g} / \mathrm{mL}$. Values are presented as mean \pm standard deviation of three determinations.

\subsubsection{Polyphenol, Flavonoids and Anthocyanin Contents}

The total polyphenolic contents (TPC) of Luma fruits and leaves were determined by the Folin-Ciocalteau method $[19,33,39]$ with some modifications. An aliquot of each processed SPE extract ( $200 \mu \mathrm{L}$, approx. $2 \mathrm{mg} / \mathrm{mL}$ ) was added to the Folin-Ciocalteau reagent ( $2 \mathrm{~mL}, 1: 10 \mathrm{v} / \mathrm{v}$ in purified water) and after $5 \mathrm{~min}$ of reaction at room temperature $\left(25^{\circ} \mathrm{C}\right), 2 \mathrm{~mL}$ of a $100 \mathrm{~g} / 1$ solution of $\mathrm{Na}_{2} \mathrm{CO}_{3}$ was added. Sixty minutes later the absorbance was measured at $710 \mathrm{~nm}$. The calibration curve was performed with gallic acid (concentrations ranging from 16 to $500 \mu \mathrm{g} / \mathrm{mL}, \mathrm{R}^{2}=0.999$ ) and the results were expressed as mg gallic acid equivalents/g dry mass. Determination of total flavonoid content (TFC) of the methanolic extracts was performed as reported previously [40] using the $\mathrm{AlCl}_{3}$ colorimetric method. Quantification was expressed by reporting the absorbance in the calibration graph of quercetin, which was used as a standard (from 0.1 to $65.0 \mu \mathrm{g} / \mathrm{mL}, \mathrm{R}^{2}=0.994$ ). Results are expressed as mg quercetin equivalents/g dry weight. The assessment of total anthocyanin content (TAC) was carried out by the $\mathrm{pH}$ differential method according to AOAC as described by [38,41]. Absorbance was measured at 510 and $700 \mathrm{~nm}$ in buffers at $\mathrm{pH} 1.0$ and 4.5. Pigment concentration is expressed as mg cyanidin 3-glucoside equivalents/g dry mass and calculated using the formula:

$$
\mathrm{TA}(\mathrm{mg} / \mathrm{g})=\frac{\mathrm{A} \times \mathrm{MW} \times \mathrm{DF} \times 10^{5}}{\varepsilon \times 1}
$$

where $\mathrm{A}=(\mathrm{A} 510 \mathrm{~nm}-\mathrm{A} 700 \mathrm{~nm}) \mathrm{pH} 1.0-(\mathrm{A} 510 \mathrm{~nm}-\mathrm{A} 700 \mathrm{~nm}) \mathrm{pH} 4.5 ; \mathrm{MW}($ molecular weight $)=$ $449.2 \mathrm{~g} / \mathrm{mol}$; $\mathrm{DF}=$ dilution factor; $1=$ cuvette pathlength in $\mathrm{cm} ; \varepsilon=26,900 \mathrm{~L} / \mathrm{mol} . \mathrm{cm}$, molar extinction coefficient for cyanidin 3-O- $\beta$-D-glucoside. $10^{3}$ : factor to convert $\mathrm{g}$ to $\mathrm{mg}$. All spectrometric measurements were performed using a Unico $2800 \mathrm{UV}-\mathrm{V}$ is spectrophotometer (Unico Instruments Co. Ltd., Shanghai, China).

\subsection{Statistical Analysis}

The statistical analysis was carried out using the originPro 9.0 software packages (Originlab Corporation, Northampton, MA, USA). The determination was repeated at least three times for each sample solution. Analysis of variance was performed using ANOVA. Significant differences between means were determined by Tukey comparison test ( $p$ values $<0.05$ were regarded as significant). 


\section{Conclusions}

Thirty one anthocyanins, three phenolic acids (feruloylquinic acid, chlorogenic and neochlorogenic acid) and six flavonols (rutin, quercetin, myricetin, hyperoside, isoquercitrin and isorhamnetin) were identified for the first time in six edible berries from the VIII region of Chile using ToF-MS. Among the 31 anthocyanins identified in the six berries under study, twenty three compounds were detected in blueberry, fourteen in calafate, nine in arrayán and six were present in meli, chequén and murta. The anthocyanins detected were mainly branched 3-O-glycoconjugates of malvidin, delphinidin, peonidin, petunidin and cyanidin. However, significant differences in the amount of anthocyanins, (which were measured individually by HPLC for the major ones and by TAC colorimetric method) were found for the six berries, which presented also different antioxidant capacities. Blueberry fruits showed the most complex anthocyanin profile, while the fruits of chequen and murta showed a simpler pattern with only six anthocyanins, whereas arrayán and chequén showed a more complex pattern. However, the fruits of calafate (B. microphylla) presented the highest antioxidant features and polyphenolic content followed by the fruits of Chilean blueberries (V. corymbosum), arrayán (L. apiculata) and meli (A. meli), which makes calafate, arrayán and meli the better candidates for industrial crop production and potential use in functional foods and nutraceuticals.

\section{Supplementary Materials}

Supplementary materials can be accessed at: http://www.mdpi.com/1420-3049/19/8/10936/s1.

\section{Acknowledgements}

This work was financially supported by the National Fund of Scientific and Technological Development of Chile (Fondecyt No. 1140178).

\section{Author Contributions}

EK, CA, BS and MS designed research; AB, MS and BS performed research and analyzed the data; MS, CA and EK wrote the paper. All authors read and approved the final manuscript.

\section{Conflicts of Interest}

The authors declare no conflict of interest.

\section{References}

1. Pennington, J.A.T.; Fisher, R.A. Food component profiles for fruit and vegetable subgroups. J. Food Compos. Anal. 2010, 23, 411-418.

2. Zamora-Ros, R.; Fedirko, V.; Trichopoulou, A.; Gonzalez, C.A.; Bamia, C.; Trepo, E.; Nothlings, U.; Duarte-Salles, T.; Serafini, M.; Bredsdorff, L.; et al. Dietary flavonoid, lignan and antioxidant capacity and risk of hepatocellular carcinoma in the European prospective investigation into cancer and nutrition study. Int. J. Cancer 2013, 133, 2429-2443. 
3. Manach, C.; Scalbert, A.; Morand, C.; Remesy, C.; Jimenez, L. Polyphenols: Food sources and bioavailability. Am. J. Clin. Nutr. 2004, 79, 727-747.

4. Pojer, E.; Mattivi, F.; Johnson, D.; Stockley, C.S. The case for anthocyanin consumption to promote human health: A review. Compr. Rev. Food Sci. F. 2013, 12, 483-508.

5. Lachman, J.; Orsák, M.; Pivec, V. Antioxidant contents and composition in some vegetables and their role in human nutrition. Hortic. Sci. 2000, 27, 65-78.

6. Delporte, C.; Backhouse, N.; Inostroza, V.; Aguirre, M.C.; Peredo, N.; Silva, X.; Negrete, R.; Miranda, H.F. Analgesic activity of Ugni molinae (murtilla) in mice models of acute pain. J. Ethnopharmacol. 2007, 112, 162-165.

7. Scheuermann, E.; Seguel, I.; Montenegro, A.; Bustos, R.; Hormazabal, E.; Quiroz, A. Evolution of aroma compounds of murtilla fruits (Ugni molinale Turcz) during storage. J. Sci. Food Agric. 2008, $88,485-492$.

8. Murillo, A. Plantes médicinales du Chili; Exposition Universelle de Paris Section Chilienne. Roger y Chernoviz: Paris, France, 1889; Volum 80, p. 234.

9. Hoffmann, A.E. Flora Silvestre de Chile, 3rd ed.; Gay, C., Ed.; Ediciones Fundacion Claudio Gay: Santiago, Chile, 1995; Volume 1, p. 258.

10. De Mösbach, E.W. Botánica indígena de Chile. In Museo Chileno de Arte Precolombino, Fundación Andes y Editorial Andrés Bello; Aldunate, C., Villagrán, C., Eds.; Editorial Andrés Bello: Santiago, Chile, 1991; pp. 95-96.

11. Mariangel, E.; Reyes-Diaz, M.; Lobos, W.; Bensch, E.; Schalchli, H.; Ibarra, P. The antioxidant properties of calafate (Berberis microphylla) fruits from four different locations in southern Chile. Cienc. Investig. Agrar. 2013, 40, 161-170.

12. Ruiz, A.; Hermosín-Gutiérrez, I.; Mardones, C.; Vergara, C.; Herlitz, E.; Vega, M.; Dorau, C.; Winterhalter, P.; von Baer, D. Polyphenols and antioxidant activity of Calafate (Berberis microphylla) fruits and other native berries from Southern Chile. J. Agric. Food Chem. 2010, 58, 6081-6089.

13. Ruiz, A.; Mardones, C.; Vergara, C.; Hermosín-Gutiérrez, I.; von Baer, D.; Hinrichsen, P.; Rodriguez, R.; Arribillaga, D.; Dominguez, E. Analysis of hydroxycinnamic acids derivatives in calafate (Berberis microphylla G. Forst) berries by liquid chromatography with photodiode array and mass spectrometry detection. J. Chromatogr. A 2013, 1281, 38-45.

14. Escribano-Bailón, M.T.; Alcalde-Eon, C.; Muñoz, O.; Rivas-Gonzalo, J.C.; Santos-Buelga, C. Anthocyanins in berries of Maqui (Aristotelia chilensis (Mol.) Stuntz). Phytochem. Anal. 2006, 17, $8-14$.

15. Ruiz, A.; Hermosín-Gutiérrez, I.; Vergara, C.; von Baer, D.; Zapata, M.; Hitschfeld, A.; Obando, L.; Mardones, C. Anthocyanin profiles in south Patagonian wild berries by HPLC-DAD-ESI-MS/MS. Food Res. Int. 2013, 51, 706-713.

16. Reynertson, K.A.; Yang, H.; Jiang, B.; Basile, M.J.; Kennelly, E.J. Quantitative analysis of antiradical phenolic constituents from fourteen edible Myrtaceae fruits. Food Chem. 2008, 109, 883-890.

17. Theoduloz, C.; Franco, L.; Ferro, E.; Schmeda Hirschmann, G. Xanthine oxidase inhibitory activity of Paraguayan Myrtaceae. J. Ethnopharmacol. 1988, 24, 179-183. 
18. Theoduloz, C.; Pacheco, P.; Schmeda Hirschmann, G. Xanthine oxidase inhibitory activity of Chilean Myrtaceae. J. Ethnopharmacol. 1991, 33, 253-255.

19. Simirgiotis, M.J.; Borquez, J.; Schmeda-Hirschmann, G. Antioxidant capacity, polyphenolic content and tandem HPLC-DAD-ESI/MS profiling of phenolic compounds from the South American berries Luma apiculata and L. chequen. Food Chem. 2013, 139, 289-299.

20. Bórquez, J.; Kennelly, E.J.; Simirgiotis, M.J. Activity guided isolation of isoflavones and hyphenated HPLC-PDA-ESI-ToF-MS metabolome profiling of Azorella madreporica Clos. from northern Chile. Food Res. Int. 2013, 52, 288-297.

21. Wu, S.-B.; Wu, J.; Yin, Z.; Zhang, J.; Long, C.; Kennelly, E.J.; Zheng, S. Bioactive and Marker Compounds from Two Edible Dark-Colored Myrciaria Fruits and the Synthesis of Jaboticabin. J. Agric. Food Chem. 2013, 61, 4035-4043.

22. Wu, S.-B.; Dastmalchi, K.; Long, C.; Kennelly, E.J. Metabolite Profiling of Jaboticaba (Myrciaria cauliflora) and Other Dark-Colored Fruit Juices. J. Agric. Food Chem. 2012, 60, 7513-7525.

23. Simirgiotis, M.J.; Ramirez, J.E.; Schmeda Hirschmann, G.; Kennelly, E.J. Bioactive coumarins and HPLC-PDA-ESI-ToF-MS metabolic profiling of edible queule fruits (Gomortega keule), an endangered endemic Chilean species. Food Res. Int. 2013, 54, 532-543.

24. Verardo, V.; Arráez-Román, D.; Segura-Carretero, A.; Marconi, E.; Fernández-Gutiérrez, A.; Caboni, M.F. Identification of buckwheat phenolic compounds by reverse phase high performance liquid chromatography-electrospray ionization-time of flight-mass spectrometry (RP-HPLC-ESI-TOF-MS). J.Cereal Sci. 2010, 52, 170-176.

25. Qiu, J.; Chen, L.; Zhu, Q.; Wang, D.; Wang, W.; Sun, X.; Liu, X.; Du, F. Screening natural antioxidants in peanut shell using DPPH-HPLC-DAD-TOF/MS methods. Food Chem. 2012, 135, 2366-2371.

26. Lätti, A.K.; Riihinen, K.R.; Jaakola, L. Phenolic compounds in berries and flowers of a natural hybrid between bilberry and lingonberry (Vaccinium intermedium Ruthe). Phytochemistry 2011, $72,810-815$.

27. Li, H.; Deng, Z.; Zhu, H.; Hu, C.; Liu, R.; Young, J.C.; Tsao, R. Highly pigmented vegetables: Anthocyanin compositions and their role in antioxidant activities. Food Res. Int. 2012, 46, 250-259.

28. Aguirre, M.J.; Isaacs, M.; Matsuhiro, B.; Mendoza, L.; Santos, L.S.; Torres, S. Anthocyanin composition in aged Chilean Cabernet Sauvignon red wines. Food Chem. 2011, 129, 514-519.

29. Wu, X.; Prior, R.L. Identification and characterization of anthocyanins by high-performance liquid chromatography-electrospray Ionization-tandem mass spectrometry in common foods in the United States: vegetables, nuts, and grains. J. Agric. Food Chem. 2005, 53, 3101-3113.

30. Abdel-Aal, E.-S.M.; Young, J.C.; Rabalski, I. Anthocyanin composition in black, blue, pink, purple, and red cereal grains. J. Agric. Food Chem. 2006, 54, 4696-4704.

31. Yousef, G.G.; Brown, A.F.; Funakoshi, Y.; Mbeunkui, F.; Grace, M.H.; Ballington, J.R.; Loraine, A.; Lila, M.A. Efficient quantification of the health-relevant anthocyanin and phenolic acid profiles in commercial cultivars and breeding selections of Blueberries (Vaccinium spp.). J. Agric. Food Chem. 2013, 61, 4806-4815. 
32. Zheng, J.; Ding, C.; Wang, L.; Li, G.; Shi, J.; Li, H.; Wang, H.; Suo, Y. Anthocyanins composition and antioxidant activity of wild Lycium ruthenicum Murr. from Qinghai-Tibet plateau. Food Chem. 2011, 126, 859-865.

33. Simirgiotis, M.J. Antioxidant Capacity and HPLC-DAD-MS Profiling of Chilean Peumo (Cryptocarya alba) Fruits and Comparison with German Peumo (Crataegus monogyna) from Southern Chile. Molecules 2013, 18, 2061-2080.

34. Schierle, J.; Pietsch, B.; Ceresa, A.; Fizet, C. Method for the determination of $\beta$-carotene in supplements and raw materials by reversed-phase liquid chromatography: Single laboratory validation. J. AOAC Int. 2004, 87, 1070-1082.

35. Bunea, A.; Rugina, D.; Sconta, Z.; Pop, R.M.; Pintea, A.; Socaciu, C.; Tabaran, F.; Grootaert, C.; Struijs, K.; VanCamp, J. Anthocyanin determination in blueberry extracts from various cultivars and their antiproliferative and apoptotic properties in B16-F10 metastatic murine melanoma cells. Phytochemistry 2013, 95, 436-444.

36. Carbone, K.; Giannini, B.; Picchi, V.; Lo Scalzo, R.; Cecchini, F. Phenolic composition and free radical scavenging activity of different apple varieties in relation to the cultivar, tissue type and storage. Food Chem. 2011, 127, 493-500.

37. Simirgiotis, M.J.; Schmeda-Hirschmann, G. Determination of phenolic composition and antioxidant activity in fruits, rhizomes and leaves of the white strawberry (Fragaria chiloensis spp. chiloensis form chiloensis) using HPLC-DAD-ESI-MS and free radical quenching techniques. J. Food Compos. Anal. 2010, 23, 545-553.

38. Benzie, I.F.F.; Strain, J.J. The ferric reducing ability of plasma (FRAP) as a measure of "Antioxidant Power": The FRAP assay. Anal.Biochem. 1996, 239, 70-76.

39. Simirgiotis, M.J.; Caligari, P.D.S.; Schmeda-Hirschmann, G. Identification of phenolic compounds from the fruits of the mountain papaya Vasconcellea pubescens A. DC. grown in Chile by liquid chromatography-UV detection-mass spectrometry. Food Chem. 2009, 115, 775-784.

40. Simirgiotis, M.J.; Adachi, S.; To, S.; Yang, H.; Reynertson, K.A.; Basile, M.J.; Gil, R.R.; Weinstein, I.B.; Kennelly, E.J. Cytotoxic chalcones and antioxidants from the fruits of Syzygium samarangense (Wax Jambu). Food Chem. 2008, 107, 813-819.

41. Lee, J.; Durst, R.W.; Wrolstad, R.E. Determination of total monomeric anthocyanin pigment content of fruit juices, beverages, natural colorants, and wines by the $\mathrm{pH}$ differential method: Collaborative study. J. AOAC Int. 2005, 88, 1269-1278.

Sample Availability: Samples of the compounds and extract of the berries are available from authors.

(C) 2014 by the authors; licensee MDPI, Basel, Switzerland. This article is an open access article distributed under the terms and conditions of the Creative Commons Attribution license (http://creativecommons.org/licenses/by/3.0/). 